\title{
FAMÍLIA, DIGNIDADE DA PESSOA HUMANA E RELATIVISMO CULTURAL
}

\section{Elisângela Padilha}

Advogada. Professora universitária no curso de Direito das Faculdades Integradas de Ourinhos - FIO (Ourinhos, SP). Graduada em Comunicação Social pela Unimar (Marília, SP). Graduada em Direito pelas Faculdades Integradas de Ourinhos - FIO (Ourinhos, SP). Especialista em Direito Civil e Processo Civil pela Projuris/FIO (Ourinhos, SP). Mestre em Ciência Jurídica pela Universidade Estadual do Norte do Paraná - UENP (Jacarezinho, PR). Autora das obras $A$ eficácia dos direitos fundamentais nas relações contratuais entre particulares, publicado pela Editora Nuria Fabris, e Novas estruturas familiares: por uma intervenção mínima do Estado, publicado pela Editora Lumen Juris. E-mail: <padilha. Im@gmail.com>.

\section{Carla Bertoncini}

Advogada. Professora universitária nos cursos de Direito das Faculdades Integradas de Ourinhos - FIO (Ourinhos, SP) e da Universidade Estadual do Norte do Paraná - UENP (Jacarezinho, PR). E-mail:<carla.bertoncini@uenp.edu.br>.

\begin{abstract}
Resumo: O presente artigo tem por objetivo investigar o que define a família no mundo contemporâneo sob o ponto de vista cultural. Seria possível, com fundamento na dignidade da pessoa humana, estabelecer um conceito multicultural de família? À família sempre coube um papel essencial na vida do homem, representando o modo pelo qual este se relaciona com o meio em que vive, priorizando a plena realização pessoal de cada membro familiar, com base no afeto, na busca pela felicidade, no respeito à dignidade da pessoa humana e seus direitos fundamentais. Família e sociedade conjugamse em uma relação sistêmica. A família deve ser entendida como a comunidade de vida material e afetiva de seus integrantes, união de esforços para o desenvolvimento de atividades materiais e sociais, convivência que promove mútua companhia, apoio moral e psicológico, na busca do melhor desenvolvimento da personalidade das pessoas que a compõem. A família não é um produto da natureza e estática no tempo, e sim um grupo dinâmico que reage e interfere na sociedade. Nesse contexto, é possível, com fundamento na dignidade da pessoa humana, buscar um conceito de família que possa ser pensado e entendido em qualquer tempo e espaço.
\end{abstract}

Palavras-chave: Família. Dignidade da pessoa humana. Cultura. Sociedade. Multiculturalismo.

Sumário: 1 Introdução - 2 Breve perfil da família no Brasil - 3 A família e o debate entre universalismo e relativismo cultural - $4 \mathrm{~A}$ dignidade da pessoa humana como fundamento para uma concepção multicultural de família - $\mathbf{5}$ Considerações finais - Referências 


\section{Introdução}

A composição familiar, no século XIX, era tipicamente patriarcal e estruturada em torno do patrimônio familiar. A família era composta pelo núcleo central (pai, esposa e filhos legítimos) e tinha representatividade religiosa, política e, especialmente, econômica. O pater familias era o grande homem dotado de autoridade máxima. Por sua vez, a mulher limitava-se à execução de tarefas domésticas e à criação dos filhos, de modo a garantir o bom andamento das diretrizes familiares. Assim, no patriarcalismo, havia lugares demarcados para um e para outro, ou seja, o lugar do homem e da mulher, do pai e da mãe.

Todavia, com a Revolução Industrial e consequente aumento da necessidade de mão de obra, a estrutura familiar foi, aos poucos, sofrendo importantes alterações. Com a inclusão da mulher no mercado de trabalho, o homem deixou de ser a única fonte de sustento da família. Diante do afastamento da mulher do ambiente exclusivamente doméstico, houve a necessidade da presença masculina para auxiliar nos afazeres domésticos e no cuidado com os filhos. Com isso, o próprio exercício da paternidade passou a ser repensado.

As lutas emancipatórias, o início do movimento feminista, a descoberta dos métodos contraceptivos e o surgimento das modernas técnicas de reprodução assistida ensejaram transformações expressivas. Finalmente, a mulher descobriu o direito à liberdade, à igualdade de oportunidades e passou a discutir a discriminação de que sempre foi alvo, não mais se sujeitando ao marido por questões de sobrevivência. Aos poucos, a estrutura vertical do caráter produtivo e reprodutivo do laço familiar que prevalecia cedeu a um convívio de maior igualdade.

Logo, aquela família constituída a partir de motivações exclusivamente econômicas cedeu espaço aos vínculos familiares mais autênticos, fundados no amor, na compreensão, deixando de lado a falsidade institucionalizada e a submissão à legalidade estrita. ${ }^{1}$ Enfim, a essência da família deixou de ser a figura paterna, e passou a ser o afeto.

Assim, a família contemporânea apresenta traços que vão além de um mero agrupamento humano. Vale dizer, a família casamentária e decorrente dos laços sagrados do matrimônio passou a coexistir com diversas modalidades de família, tais como a família monoparental, pluriparental, homoafetiva, poliafetiva, reconstituída, formada por união estável, enfim, a lista dos múltiplos arranjos familiares é extensa, pois a família tornou-se dinâmica e flexível.

DIAS, Maria Berenice. Homoafetividade e os direitos LGBTI. 6. ed. reformulada. São Paulo: Revista dos Tribunais, 2014. p. 108. 
No Brasil, especialmente a partir da Constituição Federal de 1988, ocorreram expressivas transformações na estrutura da sociedade e na própria vida das pessoas. Entre tais mudanças, destacam-se a busca pelo bem-estar de todos, a dignidade da pessoa humana, a igualdade e a liberdade, que ocasionaram um alargamento das relações pessoais, as quais certamente contribuíram para o surgimento de novas estruturas familiares.

O fato é que, apesar das inúmeras mudanças registradas no perfil das famílias no mundo inteiro, alguns grupos ainda insistem em discursos incoerentes com o atual modelo histórico da família, defendendo a manutenção do modelo monogâmico, centralizado na autoridade paterna e, rotuladamente, heterossexual.

Apesar dos significativos avanços, os valores patriarcais e o conservadorismo social persistem em nome de uma moral alegadamente civilizatória, moral esta que, no passado, provocou severas exclusões de muitas pessoas do laço social quando, por exemplo, considerava ilegítimos os filhos havidos fora da constância do casamento; quando determinados modelos familiares eram tratados como mera sociedade de fato, retirando a dignidade das pessoas que os constituíam, negando-Ihes uma série de direitos; quando existia a superioridade do homem sobre as mulheres nas relações conjugais, e o casamento era a única forma de legitimar e constituir uma família.

Mas, afinal, em nome de qual moral as novas modalidades de família são excluídas pelo ordenamento jurídico? o que existe na realidade é clara intolerância das pessoas diante de tudo aquilo que de alguma forma se destoa dos padrões vigentes, se destoa dos princípios particulares. Esta intolerância em relação ao "diverso" decorre do preconceito, o que faz com que esses novos arranjos familiares, especialmente as uniões homoafetivas, sejam desprezados e reprovados.

O fato é que à família sempre coube um papel essencial na vida do homem, representando o modo pelo qual este se relaciona com o meio em que vive, priorizando a plena realização pessoal de cada membro familiar, com base no afeto, na busca pela felicidade, no respeito à dignidade da pessoa humana e seus direitos fundamentais.

Da temática abordada, portanto, pode-se extrair o seguinte problema de pesquisa: com fundamento na dignidade da pessoa humana, é possível estabelecer um conceito universal de família? Nesse contexto, considerando que as culturas têm concepções distintas de dignidade da pessoa humana, o objetivo do presente estudo é o de investigar o que define a família no mundo contemporâneo sob o ponto de vista multicultural, a partir dos estudos realizados por Boaventura de Souza Santos, entre outros. 
Em uma sociedade democrática, são importantes os debates, pois, além de demonstrarem uma evolução do pensamento humano, contribuem para a compreensão e proteção da dignidade da pessoa humana e de sua concretização para cada ser humano, especialmente nas relações familiares. Neste sentido, o trabalho é atual e relevante para a comunidade jurídica na medida em que visa buscar contribuir com um olhar para a compreensão das novas relações familiares.

\section{Breve perfil da família no Brasil}

No decorrer de cada conjuntura histórica, a organização sociofamiliar foi sendo moldada e adaptada em consonância com os interesses políticos, econômicos, religiosos e culturais dominantes. De tal modo que, ao fenômeno familiar, implica reconhecer um constante processo de mutação e evolução, eis que influenciado por valores variados decorrentes de circunstâncias de determinada época e espaço.

Nas sociedades primitivas, as primeiras manifestações de família constituíram-se com base no instinto sexual, embora não formassem efetivamente uma família para os padrões organizacionais tal como é conhecida. Já no direito romano, a estrutura familiar era tipicamente patriarcal, destacando-se a soberania do pater familias, o casamento monogâmico e heterossexual. No período medieval, a organização familiar sofreu intensa influência religiosa, marcada pela ideia de indissolubilidade do casamento e imperatividade de procriação. Por sua vez, no mundo moderno, o casamento civil foi regulamentado, possibilitando o surgimento de outras modalidades de família. ${ }^{2}$

O fato é que os modelos de família e os papéis destinados aos homens e mulheres passaram a ser questionados e reexaminados, seja no âmbito familiar ou social. Passou-se, enfim, a questionar o próprio conceito universalizante de família como uma instituição natural e padronizada, bem como o conceito de povo, sexualidade, criança, família, homem e mulher. Essas novas abordagens são marcadas por questionamentos e movimentos sociais e culturais que provocaram alterações nas relações de trabalho, na participação política e, de modo marcante, nos padrões familiares. ${ }^{3}$

PADILHA, Elisângela. A constitucionalização do direito privado e a proteção dos direitos fundamentais nos novos arranjos familiares. Direitos Fundamentais \& Justiça, v. 9, n. 33, p. 166-184, out./dez. 2015. p. 166-184.

3 SANTIAGO, Marcelo; FEITOSA, Lourdes Conde. Família e gênero: um estudo antropológico. Mimesis, Bauru, v. 32, n. 1, p. 29-41, 2011. 
Zigmunt Bauman, em suas obras Tempos líquidos ${ }^{4}$ e Amor líquido, ${ }^{5}$ aborda as relações humanas, que se tornam cada vez mais flexíveis, em um mundo propenso a mudar com rapidez e de forma imprevisível, em um mundo que se torna cada vez mais virtual do que real, afetando os conceitos de família e comunidade. Neste contexto, há quem defenda a ideia de desestruturação familiar, esta marcada pelo aumento do número de divórcios, novas formas de uniões entre sexos, diminuição do número de filhos, desvalorização dos laços familiares, enfim, a família estaria enfraquecida, debilitada.

No Brasil, a Constituição Federal de 1988 erigiu a família como base da sociedade e, consequentemente, conferiu-Ihe especial proteção do Estado. Mas quando se diz que a família é o núcleo essencial da sociedade, é preciso ter claro que não se faz referência àquela família tal como concebida historicamente, ou seja, aquela composição familiar patrimonializada, hierarquizada e matrimonializada, predominante no século anterior e no Código Civil brasileiro de 1916. Refere-se à família tal como ela é hoje: plural. Tais mudanças no perfil da família brasileira, nas últimas décadas, foram registradas pelo IBGE. ${ }^{6}$ Entre as mudanças identificadas pelo Censo de 2010, destacam-se:

a) o percentual de uniões consensuais aumentou expressivamente, sendo a principal escolha entre pretos e pardos, o que possivelmente está relacionado a condições socioeconômicas mais precárias, haja vista que o maior percentual foi encontrado na classe de rendimento até $1 / 2$ salário mínimo, decrescendo conforme o rendimento aumentava;

b) entre os casais do mesmo sexo, $25,8 \%$ das pessoas declararam possuir superior completo e $47,4 \%$ se declararam católicos. As mulheres são maioria entre os casais homossexuais;

c) a proporção dos divorciados quase dobrou, talvez porque a legislação tenha facilitado a separação;

d) ocorreu uma pequena mudança de valores relativos ao papel da mulher na sociedade, considerando o ingresso no mercado de trabalho, o aumento da escolaridade em nível superior e a redução de fecundidade. Provavelmente isso provocou um aumento no percentual de mulheres responsáveis pela entidade doméstica;

4 BAUMAN, Zigmunt. Tempos líquidos. Tradução de Carlos Alberto Medeiros. Rio de Janeiro: Jorge Zahar, 2007.

5 BAUMAN, Zigmunt. Amor líquido: sobre a fragilidade dos laços humanos. Tradução de Carlos Alberto Medeiros. Rio de Janeiro: Jorge Zahar, 2004.

6 IBGE. Censo 2010. Disponível em: <http://censo2010.ibge.gov.br/>. Acesso em: 18 abr. 2016. A coleta do Censo Demográfico 2010 foi realizada no período de 1ํ.8 a 30.10.2010. 
e) as famílias reconstituídas, formadas após a separação ou morte de um dos cônjuges, representam $16,3 \%$ das formadas por casais. No caso, os filhos são apenas de um dos parceiros ou de ambos em relacionamentos anteriores;

f) o número de filhos que teria uma mulher caiu de maneira expressiva, pois o nível de instrução reflete redução na fecundidade;

g) o número de casais sem filhos aumentou. Fatores como aumento da participação da mulher no mercado de trabalho e envelhecimento da população certamente influenciaram o aumento da proporção de casais sem filhos. No entanto, o percentual de famílias compostas por casais com filhos é superior na área rural, devido às taxas de fecundidade historicamente mais elevadas e, também, em função dos valores culturais mais tradicionais;

h) o tipo mais frequente entre as famílias conviventes (residem na mesma unidade doméstica) é o das monoparentais femininas (53,5\%), 98,6\% delas formadas por parentes da família principal. Ao examinar o parentesco dos núcleos secundários, verifica-se que, em $78 \%$ dos casos, há presença de filhos do responsável ou do cônjuge da família principal que poderiam ser considerados membros da família principal. As monoparentais femininas são provavelmente compostas por filhas dos responsáveis e/ou dos cônjuges, que tiveram seus filhos sem contrair matrimônio ou retornaram à casa dos pais por motivo de separação ou divórcio.

Percebe-se, assim, que família e sociedade conjugam-se em uma relação sistêmica. Vale dizer, as relações familiares devem ser analisadas à luz das transformações no âmbito social, político e econômico. Não se deve olhar para a família como uma estrutura fixa no tempo. Tentar compreender a família apenas sob um ângulo de observação, isolada dos mais variados campos do conhecimento, é enxergá-la de forma míope, desvirtuada de sua real feição. Sem dúvida, torna-se necessária a compreensão da dinâmica e complexidade das modificações sociais perpetradas pelo avanço tecnológico, científico e cultural a fim de abrir espaço para esses novos arranjos familiares suscetíveis às influências da nova sociedade.

Enfim, a família deve ser entendida como a comunidade de vida material e afetiva de seus integrantes, união de esforços para o desenvolvimento de atividades materiais e sociais, convivência que promove mútua companhia, apoio moral e psicológico, na busca do melhor desenvolvimento da personalidade das pessoas que a compõem. ${ }^{7}$

POLI, Luciana Costa. Famílias simultâneas: uma realidade invisível. Revista Direitos Fundamentais \& Justiça, ano 9, n. 31, p. 56-79, abr./jun. 2015. p. 57. 


\section{A família e o debate entre universalismo e relativismo cultural}

O direito de família é o mais humano de todos os ramos do direito. Por isso, e também pelo sentido ideológico e histórico de exclusões, é que se torna imprescindivel refletir sobre o direito de família na contemporaneidade com o auxílio e pelo ângulo dos direitos humanos, cujos alicerces e elementos estão, igualmente, relacionados à noção de cidadania. ${ }^{8}$

Nesse contexto, é preciso invocar os arts. 16 e 25 da Declaração Universal dos Direitos Humanos:

Artigo 16․

I - A partir da idade núbil, o homem e a mulher têm o direito de casar e de constituir família, sem restrição alguma de raça, nacionalidade ou religião. Durante o casamento e na altura da sua dissolução, ambos têm direitos iguais.

II - O casamento não pode ser celebrado sem o livre e pleno consentimento dos futuros esposos.

III - A família é o elemento natural e fundamental da sociedade e tem direito à proteção desta e do Estado. [...]

Artigo 25․

I - [ ...].

II - A maternidade e a infância têm direito a ajuda e a assistência especiais. Todas as crianças, nascidas dentro ou fora do matrimônio, gozam da mesma proteção social.

Logo, os Estados passaram a reconhecer a liberdade dos indivíduos e eleger outras formas de composição familiar para além daquelas formadas tradicionalmente. ${ }^{9}$ No Brasil, a Constituição Federal de 1988 trouxe expressivas transformações, pois a partir de seus princípios fundamentais, entre eles o da cidadania e dignidade da pessoa humana, rompeu definitivamente com antigas concepções já consagradas, tais como a ilegitimidade dos filhos, uma vez que todas as formas de filiação foram legitimadas pelo Estado; a superioridade do homem sobre a mulher nas relações conjugais; o casamento como única forma de

8 PEREIRA, Rodrigo da Cunha. Família, direitos humanos, psicanálise e inclusão social. Revista do Ministério Público do Rio Grande do Sul, Porto Alegre, n. 58, p. 195-201, maio/ago. 2006.

9 PEREIRA, Rodrigo da Cunha. Família, direitos humanos, psicanálise e inclusão social. Revista do Ministério Público do Rio Grande do Sul, Porto Alegre, n. 58, p. 195-201, maio/ago. 2006. 
se constituir e legitimar a família. ${ }^{10}$ Com relação às novas formas de convívio, a Constituição acolheu os anseios da sociedade e abarcou pelo menos três, quais sejam: a família proveniente do casamento, a família proveniente da união estável e a família monoparental.

Assim, com base nos princípios da igualdade, liberdade e dignidade da pessoa humana, há uma tendência em muitos países do mundo de se legitimar e reconhecer as novas estruturas familiares. Nessa linha, estudos antropológicos realizados com o objetivo de identificar os modelos básicos de família demonstram que não é fácil catalogar o grande número de famílias existentes justamente porque a família não é um produto da natureza e estática no tempo, e sim um grupo dinâmico que reage e interfere na sociedade. É preciso considerar, ainda, o que as pessoas envolvidas entendem por família e, por conseguinte, o seu olhar sobre os demais elementos que compõem a família. Se considerar as uniões homoafetivas, por exemplo, e a tecnologia de reprodução artificial existente, as possibilidades e existência de novos arranjos familiares são muitas. ${ }^{11}$

Sobre o tema, a antropóloga Cláudia Fonseca define dinâmicas familiares:

[...] a relação marcada pela identificação estreita e duradoura entre determinadas pessoas que reconhecem entre elas certos direitos e obrigações mútuos. Essa identificação pode ter origem em fatos alheios à vontade da pessoa (laços biológicos, territoriais), em alianças conscientes e desejadas (casamento, compadrio, adoção) ou em atividades realizadas em comum (compartilhar o cuidado de uma criança ou de um ancião, por exemplo). ${ }^{12}$

Logo, para a autora, “os aspectos biológicos, territoriais, as alianças conscientes e as atividades realizadas em comum são vistos apenas como os meios pelos quais ocorrem as uniões entre os indivíduos que se configuram em

10 PEREIRA, Rodrigo da Cunha. Princípios fundamentais e norteadores para a organização jurídica da família. Tese (Doutor em Direito) - Programa de Pós-Graduação, Faculdade de Direito, Universidade Federal do Paraná - UFPR, Curitiba, 2004. Disponível em: <http://dspace.c3sl.ufpr.br/dspace/bitstream/ handle/1884/2272/Tese_Dr.\%20Rodrigo\%20da?sequence=1>. Acesso em: 19 set. 2014.

11 SANTIAGO, Marcelo; FEITOSA, Lourdes Conde. Família e gênero: um estudo antropológico. Mimesis, Bauru, v. 32, n. 1, p. 29-41, 2011.

12 FONSECA, C. Concepções de família e práticas de intervenção: uma contribuição antropológica. Saúde e Sociedade, São Paulo, v. 14, n. 2, p. 50-59, maio/ago. 2005. Disponível em: <www.scielo.br/pdf/ sausoc/v14n2/06.pdf>. Acesso em: 11 dez. 2010. 
uma família". ${ }^{13}$ "Um grupo de pessoas é reconhecido como família quando se configura como uma relação de plena reciprocidade entre os sexos [...]". ${ }^{14}$

Enfim, apesar de toda a variedade e diversidade de cultura, religião e credos, valores morais, seria possível estabelecer um conceito universal de família? Para tanto, é necessário retomar o debate entre os universalistas e os relativistas culturais. Afinal, as normas de direitos humanos possuem um caráter universal ou são relativamente culturais? Flávia Piovesan discorre sobre o tema:

Para os universalistas, os direitos humanos decorrem da dignidade humana, enquanto valor intrínseco à condição humana. Defende-se, nesta perspectiva, o mínimo ético irredutivel - ainda que possa se discutir o alcance deste "mínimo ético". Para os relativistas, a noção de direitos está estritamente relacionada ao sistema político, econômico, cultural, social e moral vigente em determinada sociedade. Cada cultura possui seu próprio discurso acerca dos direitos fundamentais, que está relacionado às específicas circunstâncias culturais e históricas de cada sociedade. Não há moral universal, já que a história do mundo é a história de uma pluralidade de culturas. Há uma pluralidade de culturas no mundo e estas culturas produzem seus próprios valores. ${ }^{15}$

Além disso, é preciso destacar as diversas correntes relativistas existentes. Existe o chamado relativismo cultural radical que concebe a cultura como a única fonte de validade de um direito ou regra moral. Por sua vez, existe o relativismo cultural forte, que concebe a cultura como a principal fonte de validade de um direito ou regra moral. Por fim, os adeptos do relativismo cultural fraco sustentam que a cultura pode ser uma importante fonte de validade de um direito ou regra moral. ${ }^{16}$

Neste debate, destaca-se a visão de Boaventura de Souza Santos, para quem deve-se defender uma concepção multicultural de direitos humanos, inspirada no diálogo entre as culturas, a compor um multiculturalismo emancipatório. Segundo autor:

13 SANTIAgO, Marcelo; FEITOSA, Lourdes Conde. Família e gênero: um estudo antropológico. Mimesis, Bauru, v. 32, n. 1, p. 29-41, 2011.

14 PETRINI, J. C. Pós-modernidade e família: um itinerário de compreensão. Bauru: EDUSC, 2003. p. 72.

15 PIOVESAN, Flávia. Direito constitucional - Módulo V. Caderno de Direito Constitucional, Porto Alegre, 2006. Disponível em: <http://www.dhnet.org.br/direitos/militantes/flaviapiovesan/piovesan_dh_direito_ constitucional.pdf>. Acesso em: 20 abr. 2016.

16 DONNELLY, Jack. Universal human rights in theory and practice. Ithaca, NY: Cornell University Press, 1989. p. 109-110. 
[...] os direitos humanos têm que ser reconceptualizados como multiculturais. O multiculturalismo, tal como eu o entendo, é pré-condição de uma relação equilibrada e mutuamente potenciadora entre a competência global e a legitimidade local, que constituem os dois atributos de uma política contra hegemônica de direitos humanos no nosso tempo. ${ }^{17}$

Defende-se, portanto, a abertura de um diálogo entre as diferentes culturas, com respeito à diversidade e construção de mecanismos de reconhecimento de que o outro é um ser pleno de dignidade e direitos, que é uma condição necessária para a celebração de uma cultura de direitos humanos, guiada pela observância do mínimo ético irredutível, alcançado por um universalismo de confluência. ${ }^{18}$ Afinal, como assevera o art. 1ำ da Declaração dos Direitos do Homem e do Cidadão, votada pela Assembleia Nacional francesa em 1789, “as distinções sociais só podem fundar-se na utilidade comum", para que alguns cidadãos não sejam mais iguais que os outros. ${ }^{19}$

Para Flávia Piovesan, citando Joaquín Herrera Flores, deve existir um universalismo de confluência com as seguintes características:

[...] fomentado pelo ativo protagonismo da sociedade civil internacional, a partir de suas demandas e reivindicações morais, é que assegurará a legitimidade do processo de construção de parâmetros internacionais mínimos voltados à proteção dos direitos humanos. Deve haver sim o respeito às diversidades, no entanto, isso não deve servir de justificativa para não se reconhecer ao próximo a dignidade que lhe é inerente, dando-lhe como norte o princípio da igualdade, aquele que orienta toda a ideia de justiça buscada pela sociedade contemporânea. A diferença não pode ser mais utilizada para a aniquilação de direitos, mas sim, para a promoção de direitos, surgindo ao lado do direito à igualdade, o direito à diferença. ${ }^{20}$

Por sua vez, segundo David Sánchez Rubio:

17 SANTOS, Boaventura de Souza. Uma concepção multicultural de direitos humanos. Revista Lua Nova, São Paulo, v. 39, 1997. p. 112.

18 PIOVESAN, Flávia. Direito constitucional - Módulo V. Caderno de Direito Constitucional, Porto Alegre, 2006. p. 14. Disponível em: <http://www.dhnet.org.br/direitos/militantes/flaviapiovesan/piovesan_dh_direito_ constitucional.pdf>. Acesso em: 20 abr. 2016.

19 COMPARATO, Fábio Konder. Ética: direito, moral e religião no mundo moderno. São Paulo: Companhia das Letras, 2006. p. 624.

20 PIOVESAN, Flávia. Direitos humanos e o direito constitucional internacional. 13. ed. São Paulo: Saraiva, 2012. 
La conformación de un mundo global ha provocado la conciencia de un destino común para toda la humanidad. La globalización y sus diversos procesos han posibilitado espacios de interconexión entre las personas pertenecientes a diferentes puntos de la Tierra. La convivencia entre los seres humanos ha alcanzado dimensiones planetarias, articulándose múltiples y heterogéneos ámbitos tanto de jerarquías y subordinaciones, como de horizontalidades y solidaridades. Vivimos en una sociedad global, distinta del pasado por su incrementada complejidad e integración. Hemos llegado a la conciencia de que el mundo es un lugar único en el que países, civilizaciones, pueblos y culturas en apariencia separadas, simultáneamente, son inseparables. Asimismo, desesperanza y esperanza, pesimismo y optimismo se unen y se funden para mostrar la contradictoriedad que tan perturbada y tan desorientada mantiene a la comunidad internacional. ${ }^{21}$

Assim, a relação entre universalismo e relativismo cultural não pode ser enfrentada de forma ferrenha e oposta ao extremo. É preciso, pois, que se esteja aberto a um diálogo permanente e um contínuo processo de construção sem oposições dualistas.

\section{A dignidade da pessoa humana como fundamento para uma concepção multicultural de família}

Inicialmente, torna-se necessária uma breve exposição acerca da dimensão cultural da dignidade da pessoa humana, pois, diante da riqueza da vida, da diversidade axiológica, das particularidades e complexidades do ambiente em que se desenvolve a personalidade de cada pessoa, a dignidade humana é mais bem compreendida quando separada em níveis de análise.

Os direitos humanos são mutáveis e estão em permanente processo de construção e desenvolvimento, podendo variar conforme o desenvolvimento político, econômico e social. A propósito, Hannah Arendt afirma que os direitos

21 SÁNCHEZ RUBIO, David. Reflexiones e (im)precisiones en torno a la intervención humanitaria y los derechos humanos. In: SÁNCHEZ RUBIO, David; FLORES, Joaquín Herrera; CARVALHO, Salo de (Org.). Direitos humanos e globalização: fundamentos e possibilidades desde a teoria crítica. Anuário IberoAmericano de Direitos Humanos (2003/2004). Porto Alegre: EDIPUCRS, 2010. Disponível em: <http:// www.pucrs.br/edipucrs/direitoshumanos.pdf>. Acesso em: 20 jul. 2017. 
humanos não nascem de uma só vez, pois estão em constante construção e reconstrução. ${ }^{22}$

Tais direitos se modificam conforme as condições históricas, ou seja, os carecimentos e os interesses, as classes no poder, os meios disponíveis para a realização deles, as transformações técnicas etc. ${ }^{23}$ Logo, direitos que foram declarados absolutos no final do século XVIII, como a propriedade sacre et inviolable, foram submetidos a radicais limitações nas declarações contemporâneas. Por outro lado, direitos que as declarações do século XVIII nem sequer mencionavam, como os direitos sociais, foram proclamados, com enorme amplitude, a partir do século XX. Além disso, no futuro, surgirão novas dimensões de direitos fundamentais, em decorrência do progresso cibernético e da evolução científica e tecnológica. Portanto, o que é fundamental em determinada época histórica e para determinada civilização pode não ser mais para a mesma sociedade em outro contexto temporal.

De igual modo, a dignidade da pessoa humana, ainda mais por possuir conceito vago e aberto, não pode ser considerada unicamente algo inerente à natureza humana no sentido de uma característica inata pura e simplesmente, sendo produto da evolução cultural decorrente da construção histórica fruto de distintas gerações e da humanidade em seu todo. ${ }^{24}$

A dimensão cultural da dignidade da pessoa humana concebe as formas e as condições como a dignidade humana é inserida por cada grupo social no decorrer da história. Ganham destaque as peculiaridades culturais e suas práticas, variáveis no tempo e no espaço, buscando-se uma compreensão ética dos intuitos de cada grupo social, a fim de se construírem significados que tenham capacidade de serem entendidos interculturalmente. ${ }^{25}$

Todas as culturas possuem concepções distintas de dignidade humana a partir de suas demandas e reivindicações morais, algumas mais amplas do que outras, com um círculo de reciprocidade mais largo ou mais restrito. ${ }^{26}$ Por

22 ARENDT, Hannah. Origens do totalitarismo. Tradução de Roberto Raposo. Rio de Janeiro: Companhia das Letras, 2004. p. 332-333.

23 BOBBIO, Norberto. A era dos direitos. Tradução de Carlos Nelson Coutinho. Rio de Janeiro: Elsevier, 2004. p. 18.

24 SARLET, Ingo Wolfgang. As dimensões da dignidade da pessoa humana: construindo uma compreensão jurídico-constitucional necessária e possível. In: SARLET, Ingo Wolfgang (Org.). Dimensões da dignidade: ensaios de filosofia do direito e direito constitucional. Porto Alegre: Livraria do Advogado, 2005. p. 373.

25 HÖFFE, Otfried. A democracia no mundo de hoje. Tradução de Tito Lívio Cruz Romão. São Paulo: Martins Fontes, 2005. p. 77-78; BAEZ, Narciso Leandro Xavier. A morfologia dos direitos fundamentais e os problemas metodológicos da concepção de dignidade humana em Robert Alexy. In: ALEXY, Robert; BAEZ, Narciso Leandro Xavier; SILVA, Rogério Luiz Nery da (Org.). Dignidade humana e direitos sociais e nãopositivismo. Florianópolis: Qualis 2015. p. 65.

26 SANTOS, Boaventura de Souza. Direitos humanos: os desafios da interculturalidade. Revista Direitos Humanos, v. 2, jun. 2009. p. 14. Disponivel em: <http://www.boaventuradesousasantos.pt/media/ Direitos\%20Humanos_Revista\%20Direitos\%20Humanos2009.pdf>. Acesso em: 21 abr. 2016. 
exemplo, na cultura islâmica, a qual se baseia na moral religiosa para normatizar as condutas sociais, verifica-se que existe, nos textos sagrados, uma preocupação constante com a preservação da dignidade humana, que é instituída por meio de ensinamentos que resguardam os diversos modos de sua efetivação, tais como a vida, a liberdade, a igualdade, entre outros. ${ }^{27}$ Sobre o tema, Boaventura de Souza Santos parte das seguintes premissas:

As culturas possuem concepções de dignidade humana, mas nem todas elas a concebem em termos de Direitos Humanos. Além disso, todas as culturas são incompletas e problemáticas nas suas concepções de dignidade humana. Se cada cultura fosse tão completa como se julga, existiria apenas uma só cultura. Aumentar a consciência de incompletude cultural é uma das tarefas prévias à construção de uma concepção multicultural de Direitos Humanos. A quarta premissa é que todas as culturas têm versões diferentes de dignidade humana, algumas mais amplas do que outras, algumas com um círculo de reciprocidade mais largo do que outras, algumas mais abertas a outras culturas do que outras. ${ }^{28}$

Outra cultura que merece ser mencionada é a de alguns povos africanos, os quais adotam um antigo código moral chamado ubuntu, que enfatiza a importância da hospitalidade, do respeito e da generosidade que os indivíduos devem ter uns para com os outros, pelo fato de pertencerem a uma única família humana. ${ }^{29}$

Em contrapartida, destaca-se, negativamente, a posição atualmente adotada pela França a respeito da proibição ou restrição do uso da burca em lugares públicos, fundamentada na concepção moral de dignidade humana, com absoluto desrespeito às crenças dessas mulheres que acreditam no seu uso como um modo de realização de sua dignidade.

Com efeito, na dimensão cultural, a dignidade da pessoa humana é implementada a partir de esforços coletivos para juntos se alcançar um mundo melhor.

27 PISCATORI, James P. Human rights in Islamic political culture. In: THOMPSON, Kenneth W. (Org.). The moral imperativs of human rights: a world survey. Washington: University Press of America, 1980. p. 152-153.

28 SANTOS, Boaventura de Souza. Direitos humanos: os desafios da interculturalidade. Revista Direitos Humanos, v. 2, jun. 2009. Disponível em: <http://www.boaventuradesousasantos.pt/media/Direitos\%20 Humanos_Revista\%20Direitos\%20Humanos2009.pdf>. Acesso em: 21 abr. 2016.

29 BAEZ, Narciso Leandro Xavier. A morfologia dos direitos fundamentais e os problemas metodológicos da concepção de dignidade humana em Robert Alexy. In: ALEXY, Robert; BAEZ, Narciso Leandro Xavier; SILVA, Rogério Luiz Nery da (Org.). Dignidade humana e direitos sociais e não-positivismo. Florianópolis: Qualis 2015. p. 54. 
Para tanto, é imprescindível um diálogo entre as diferentes culturas, para que prevaleça a concepção multicultural de direitos humanos. ${ }^{30}$

No Brasil, a Constituição Federal de 1988, ao instituir o Estado Democrático de Direito, fixou como seu fundamento a dignidade da pessoa humana (art. 1ํㅡ, inc. III). Igualmente a Lei Fundamental da República Federal da Alemanha estabelece que a dignidade humana é intangivel. Respeitá-la e protegê-la é obrigação de todo o poder público. ${ }^{31}$ Por sua vez, a Declaração Universal dos Direitos Humanos, logo em seu preâmbulo, também reconheceu que a dignidade é inerente a todos os membros da família humana e dos seus direitos iguais e inalienáveis constitui o fundamento da liberdade, da justiça e da paz no mundo.

A dignidade da pessoa humana é, acima de tudo, multidimensional, podendo ser associada a um amplo espectro de condições inerentes à existência humana, tais como a própria vida, a integridade física e psíquica, a plenitude moral, a liberdade, as condições materiais de bem-estar etc. ${ }^{32}$ Assim, a dignidade humana representa a possibilidade de cada pessoa de realizar o próprio projeto de vida, que a comunidade política deve proteger. ${ }^{33}$

Importante destacar, todavia, que a proteção aos direitos humanos deixou de ser somente uma constante dos discursos bem-intencionados, para se traduzir em uma realidade atuante na defesa dos direitos, liberdades e garantias fundamentais. De nada adianta a mera afirmação do respeito à dignidade humana, à liberdade. Pouco vale sustentar a igualdade de todos perante a lei, dizer que homens e mulheres são iguais, que não são admitidos preconceitos ou qualquer outra forma de discriminação se não houver instrumentos que, efetivamente, obstem tais situações. ${ }^{34}$

Feitas tais observações acerca da dignidade da pessoa humana, verifica-se que o que garante a existência de uma família seguramente não é o vínculo jurídico, nem mesmo os laços biológicos de filiação são garantidores. Tais relações são da ordem da cultura, e não da natureza. Se assim fosse não seria possível o milenar instituto da adoção, por exemplo. Deve-se, então, partir da compreensão, e da

30 "Os direitos humanos têm que ser reconceptualizados como multiculturais. O multiculturalismo, tal como eu o entendo, é pré-condição de uma relação equilibrada e mutuamente potenciadora entre a competência global e a legitimidade local, que constituem os dois atributos de uma política contra hegemônica de direitos humanos no nosso tempo" (SANTOS, Boaventura de Souza. Uma concepção multicultural de direitos humanos. Revista Lua Nova, São Paulo, v. 39, 1997. p. 112).

31 Art. 1ํ da Lei Fundamental da República Federal da Alemanha.

32 VILHENA, Oscar Vieira. Direitos fundamentais: uma leitura da jurisprudência do STF. São Paulo: Malheiros, 2006. p. 64

33 RIDOLA, Paolo. A dignidade da pessoa humana e o "princípio liberdade" na cultura constitucional europeia. Tradução de Carlos Luiz Strapazzon. Porto Alegre: Livraria do Advogado, 2014. p. 115-116.

34 DIAS, Maria Berenice. Homoafetividade e os direitos LGBTI. 6. ed. reformulada. São Paulo: Revista dos Tribunais, 2014. p. 120. 
constatação, de que é possível estabelecer um conceito universal para família, revisitar o inc. III do art. 16 da Declaração Universal dos Direitos do Homem, já que família não é natural, mas essencialmente cultural. ${ }^{35}$

É claro que estabelecer um conceito multicultural de família não é tarefa fácil, pois, conforme exposto, há uma pluralidade de culturas no mundo e cada uma dessas culturas produz os seus próprios valores, crenças e discursos. 0 próprio conceito de dignidade da pessoa humana varia no tempo e espaço. Todavia, a cultura não é a única fonte de validade de um direito ou regra moral como pretendem os adeptos do relativismo cultural forte. Por outro lado, não é possível desprezar a cultura como almejam os universalistas. Ou seja, é preciso respeitar a diversidade e reconhecer o outro como ser pleno de dignidade e direitos.

Defende-se, portanto, que é possível, com fundamento na dignidade da pessoa humana, buscar um conceito de família que esteja acima de conceitos morais, muitas vezes estigmatizantes. É imperioso buscar um conceito de família que possa ser pensado e entendido em qualquer tempo e espaço, já que família foi, e sempre será, a célula básica da sociedade. ${ }^{36}$ Independentemente da época e espaço, é possível definir a família como uma estruturação psíquica em que cada membro ocupa um lugar, uma função. Lugar de pai, lugar de mãe, lugar de filhos, sem, no entanto, estarem necessariamente ligados biologicamente. É essa estruturação familiar que existe antes, e acima do direito, que interessa trazer para o mundo jurídico e que permite que o indivíduo possa, inclusive, existir como cidadão. ${ }^{37}$ É a família que cria a consciência e o sentimento de pertencimento à comunidade.

\section{Considerações finais}

À família sempre coube um papel essencial na vida do homem, representando o modo pelo qual este se relaciona com o meio em que vive, priorizando a plena realização pessoal de cada membro familiar, com base no afeto, na busca pela felicidade, no respeito à dignidade da pessoa humana e seus direitos fundamentais.

35 PEREIRA, Rodrigo da Cunha. Família, direitos humanos, psicanálise e inclusão social. Revista do Ministério Público do Rio Grande do Sul, Porto Alegre, n. 58, p. 195-201, maio/ago. 2006.

36 PEREIRA, Rodrigo da Cunha. Família, direitos humanos, psicanálise e inclusão social. Revista do Ministério Público do Rio Grande do Sul, Porto Alegre, n. 58, p. 195-201, maio/ago. 2006.

37 PEREIRA, Rodrigo da Cunha. Família, direitos humanos, psicanálise e inclusão social. Revista do Ministério Público do Rio Grande do Sul, Porto Alegre, n. 58, p. 195-201, maio/ago. 2006. 
Ao fenômeno familiar implica reconhecer um constante processo de mutação e evolução, eis que influenciado por valores variados decorrentes de circunstâncias de determinada época e espaço.

Família e sociedade conjugam-se em uma relação sistêmica. Ou seja, as relações familiares devem ser analisadas à luz das transformações no âmbito social, político e econômico.

Assim, a família deve ser entendida como a comunidade de vida material e afetiva de seus integrantes, união de esforços para o desenvolvimento de atividades materiais e sociais, convivência que promove mútua companhia, apoio moral e psicológico, na busca do melhor desenvolvimento da personalidade das pessoas que a compõem. ${ }^{38}$

Com base nos princípios da igualdade, liberdade e dignidade da pessoa humana, há uma tendência em muitos países do mundo de se legitimar e reconhecer as novas estruturas familiares, embora não seja tarefa fácil identificar os modelos básicos de famílias existentes justamente porque, como já ressaltado, a família não é um produto da natureza e estática no tempo, e sim um grupo dinâmico que reage e interfere na sociedade.

Defende-se, portanto, a abertura de um diálogo entre as diferentes culturas, com respeito à diversidade e construção de mecanismos de reconhecimento de que o outro é um ser pleno de dignidade e direitos, que é uma condição necessária para a celebração de uma cultura de direitos humanos, guiada pela observância do mínimo ético irredutível, alcançado por um universalismo de confluência. ${ }^{39}$

Verifica-se, enfim, que o que garante a existência de uma família seguramente não é o vínculo jurídico, nem mesmo os laços biológicos de filiação são garantidores. Tais relações são da ordem da cultura, e não da natureza.

Logo, estabelecer um conceito universal de família não é tarefa fácil, pois o próprio conceito de dignidade da pessoa humana varia no tempo e espaço. Todavia, a cultura não é a única fonte de validade de um direito ou regra moral como pretendem os adeptos do relativismo cultural forte. Por outro lado, não é possível desprezar a cultura como almejam os universalistas. Ou seja, é preciso respeitar a diversidade e reconhecer o outro como ser pleno de dignidade e direitos.

Defende-se, portanto, que é possível, com fundamento na dignidade da pessoa humana, buscar um conceito de família que possa ser pensado e entendido em qualquer tempo e espaço, já que família foi, e sempre será, a célula

38 POLI, Luciana Costa. Famílias simultâneas: uma realidade invisível. Revista Direitos Fundamentais \& Justiça, ano 9, n. 31, p. 56-79, abr./jun. 2015. p. 57.

39 PIOVESAN, Flávia. Direito constitucional - Módulo V. Caderno de Direito Constitucional, Porto Alegre, 2006. p. 14. Disponível em: <http://www.dhnet.org.br/direitos/militantes/flaviapiovesan/piovesan_dh_direito_ constitucional.pdf>. Acesso em: 20 abr. 2016. 
básica da sociedade..$^{40}$ Independentemente da época e espaço, é possível definir a família como uma estruturação psíquica em que cada membro ocupa um lugar, uma função. Lugar de pai, lugar de mãe, lugar de filhos, sem, no entanto, estarem necessariamente ligados biologicamente. É essa estruturação familiar que existe antes, e acima do direito, que interessa trazer para o mundo jurídico e que permite que o indivíduo possa, inclusive, existir como cidadão. ${ }^{41}$ É a família que cria a consciência e o sentimento de pertencimento à comunidade.

\title{
Family, dignity of the human person and cultural relativism
}

\begin{abstract}
The present article aims to investigate what defines the family in the contemporary world from the cultural point of view. Would it be possible, based on the dignity of the human person, to establish a multicultural concept of family? The family has always played an essential role in the life of man, representing the way in which he relates to the environment in which he lives, prioritizing the full personal fulfillment of each family member, based on affection, the search for happiness, respect for Dignity of the human person and their fundamental rights. Family and society combine in a systemic relationship. The family should be understood as the community of material and affective life of its members, union of efforts for the development of material and social activities, coexistence that promotes mutual company, moral and psychological support, in the search for the best personality development of the people who Make it up. The family is not a product of nature and static in time, but a dynamic group that reacts and interferes in society. In this context, it is possible, based on the dignity of the human person, to seek a concept of family that can be thought and understood in any time and space.
\end{abstract}

Keywords: Family. Dignity of human person. Culture. Society. Multiculturalism.

Summary: $\mathbf{1}$ Introduction - $\mathbf{2}$ Brief profile of the family in Brazil - $\mathbf{3}$ Family and the debate between universalism and cultural relativism $\mathbf{- 4}$ The dignity of the human person as the basis for a multicultural conception of the family - $\mathbf{5}$ Final considerations - References

\section{Referências}

ARENDT, Hannah. Origens do totalitarismo. Tradução de Roberto Raposo. Rio de Janeiro: Companhia das Letras, 2004.

BAEZ, Narciso Leandro Xavier. A morfologia dos direitos fundamentais e os problemas metodológicos da concepção de dignidade humana em Robert Alexy. In: ALEXY, Robert; BAEZ, Narciso Leandro Xavier; SILVA, Rogério Luiz Nery da (Org.). Dignidade humana e direitos sociais e não-positivismo. Florianópolis: Qualis 2015.

40 PEREIRA, Rodrigo da Cunha. Família, direitos humanos, psicanálise e inclusão social. Revista do Ministério Público do Rio Grande do Sul, Porto Alegre, n. 58, p. 195-201, maio/ago. 2006.

41 PEREIRA, Rodrigo da Cunha. Família, direitos humanos, psicanálise e inclusão social. Revista do Ministério Público do Rio Grande do Sul, Porto Alegre, n. 58, p. 195-201, maio/ago. 2006. 
BAUMAN, Zigmunt. Amor líquido: sobre a fragilidade dos laços humanos. Tradução de Carlos Alberto Medeiros. Rio de Janeiro: Jorge Zahar, 2004.

BAUMAN, Zigmunt. Tempos líquidos. Tradução de Carlos Alberto Medeiros. Rio de Janeiro: Jorge Zahar, 2007.

BOBBIO, Norberto. A era dos direitos. Tradução de Carlos Nelson Coutinho. Rio de Janeiro: Elsevier, 2004.

COMPARATO, Fábio Konder. Ética: direito, moral e religião no mundo moderno. São Paulo: Companhia das Letras, 2006.

DIAS, Maria Berenice. Homoafetividade e os direitos LGBTI. 6. ed. reformulada. São Paulo: Revista dos Tribunais, 2014.

DONNELLY, Jack. Universal human rights in theory and practice. Ithaca, NY: Cornell University Press, 1989.

FONSECA, C. Concepções de família e práticas de intervenção: uma contribuição antropológica. Saúde e Sociedade, São Paulo, v. 14, n. 2, p. 50-59, maio/ago. 2005. Disponível em: <www. scielo.br/pdf/sausoc/v14n2/06.pdf>. Acesso em: 11 dez. 2010.

HÖFFE, Otfried. A democracia no mundo de hoje. Tradução de Tito Lívio Cruz Romão. São Paulo: Martins Fontes, 2005.

IBGE. Censo 2010. Disponível em: <http://censo2010.ibge.gov.br/>. Acesso em: 18 abr. 2016.

PADILHA, Elisângela. A constitucionalização do direito privado e a proteção dos direitos fundamentais nos novos arranjos familiares. Direitos Fundamentais \& Justiça, v. 9, n. 33, p. 166-184, out./dez. 2015.

PEREIRA, Rodrigo da Cunha. Família, direitos humanos, psicanálise e inclusão social. Revista do Ministério Público do Rio Grande do Sul, Porto Alegre, n. 58, p. 195-201, maio/ago. 2006.

PEREIRA, Rodrigo da Cunha. Princípios fundamentais e norteadores para a organização jurídica da família. Tese (Doutor em Direito) - Programa de Pós-Graduação, Faculdade de Direito, Universidade Federal do Paraná - UFPR, Curitiba, 2004. Disponível em: <http://dspace.c3sl. ufpr.br/dspace/bitstream/handle/1884/2272/Tese_Dr.\%20Rodrigo\%20da?sequence=1>. Acesso em: 19 set. 2014.

PETRINI, J. C. Pós-modernidade e família: um itinerário de compreensão. Bauru: EDUSC, 2003.

PIOVESAN, Flávia. Direito constitucional - Módulo V. Caderno de Direito Constitucional, Porto Alegre, 2006. Disponível em: <http://www.dhnet.org.br/direitos/militantes/flaviapiovesan/ piovesan_dh_direito_constitucional.pdf>. Acesso em: 20 abr. 2016.

PIOVESAN, Flávia. Direitos humanos e o direito constitucional internacional. 13. ed. São Paulo: Saraiva, 2012.

PISCATORI, James P. Human rights in Islamic political culture. In: THOMPSON, Kenneth W. (Org.). The moral imperativs of human rights: a world survey. Washington: University Press of America, 1980. 
POLI, Luciana Costa. Famílias simultâneas: uma realidade invisível. Revista Direitos Fundamentais \& Justiça, ano 9, n. 31, p. 56-79, abr./jun. 2015.

RIDOLA, Paolo. A dignidade da pessoa humana e o "princípio liberdade" na cultura constitucional europeia. Tradução de Carlos Luiz Strapazzon. Porto Alegre: Livraria do Advogado, 2014.

SÁNCHEZ RUBIO, David. Reflexiones e (im)precisiones en torno a la intervención humanitaria y los derechos humanos. In: SÁNCHEZ RUBIO, David; FLORES, Joaquín Herrera; CARVALHO, Salo de (Org.). Direitos humanos e globalização: fundamentos e possibilidades desde a teoria crítica. Anuário Ibero-Americano de Direitos Humanos (2003/2004). Porto Alegre: EDIPUCRS, 2010. Disponivel em: <http://www.pucrs.br/edipucrs/direitoshumanos.pdf>. Acesso em: 20 jul. 2017.

SANTIAGO, Marcelo; FEITOSA, Lourdes Conde. Família e gênero: um estudo antropológico. Mimesis, Bauru, v. 32, n. 1, p. 29-41, 2011.

SANTOS, Boaventura de Souza. Direitos humanos: os desafios da interculturalidade. Revista Direitos Humanos, v. 2, jun. 2009. Disponivel em: <http://www.boaventuradesousasantos. pt/media/Direitos\%20Humanos_Revista\%20Direitos\%20Humanos2009.pdf>. Acesso em: 21 abr. 2016.

SANTOS, Boaventura de Souza. Uma concepção multicultural de direitos humanos. Revista Lua Nova, São Paulo, v. 39, 1997.

SARLET, Ingo Wolfgang. As dimensões da dignidade da pessoa humana: construindo uma compreensão jurídico-constitucional necessária e possível. In: SARLET, Ingo Wolfgang (Org.). Dimensões da dignidade: ensaios de filosofia do direito e direito constitucional. Porto Alegre: Livraria do Advogado, 2005.

VILHENA, Oscar Vieira. Direitos fundamentais: uma leitura da jurisprudência do STF. São Paulo: Malheiros, 2006.

Informação bibliográfica deste texto, conforme a NBR 6023:2002 da Associação Brasileira de Normas Técnicas (ABNT):

PADILHA, Elisângela; BERTONCINI, Carla. Família, dignidade da pessoa humana e relativismo cultural. Direitos Fundamentais \& Justiça, Belo Horizonte, ano 11, n. 37 , p. 105-123, jul./dez. 2017.

Recebido em: 14.12.2016

Pareceres: 20.04.2017 e 25.06.2017

Aprovado em: 17.10.2017 